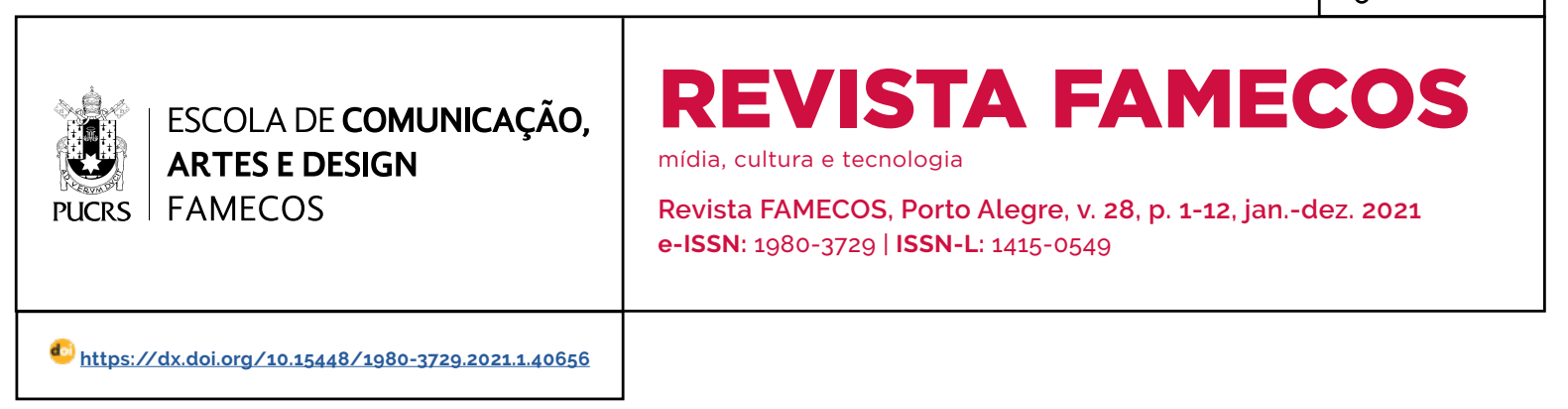

SEÇÃO: JORNALISMO

\title{
O que pensam os jornalistas brasileiros sobre a transparência das suas práticas? ${ }^{1}$
}

\author{
What do Brazilian journalists think about the transparency of their practices?
}

\author{
Rogério Christofoletti ${ }^{2}$ \\ orcid.org/0000-0003-1065-4764 \\ rogerio.christofoletti@ufsc.br
}

Recebido em: 11 abr. 2021. Aprovado em: 19 mai. 2021. Publicado em: 03 set. 2021.

\section{(c) (i)}

Artigo está licenciado sob forma de uma licença Creative Commons Atribuição 4.0 Internacional.
Resumo: Neste artigo, apresentamos elementos da percepção dos jornalistas sobre a transparência em sua profissão. Os dados referem-se ao contexto brasileiro e foram colhidos em 2020, por meio de um inquérito online, obtendo 353 respostas de todas as regiões do país. O questionário abordou impressões, atitudes e condições ambientais, no que se refere a comportamentos e disposições de maior abertura sobre a prática profissional. Este artigo se detém sobre a fração das questões (Q1-Q17) que ajuda a compor uma percepção corporativa sobre a transparência, explorando opiniões sobre os pares e sobre as próprias atitudes. Entre outros aspectos, os resultados revelam contradições entre as representações que os jornalistas fazem de si mesmos e suas práticas cotidianas. Eles se veem mais transparentes do que mostram seus gestos, o que permite entrever alguma indisposição para abertura da profissão ao público. Traços de uma cultura profissional decantada, entre outros fatores, ajudam a justificar tais comportamentos. Palavras-chave: Transparência. Percepção profissional. Jornalistas brasileiros.

Abstract: In this article, we present elements of journalists' perception of transparency in their profession. The data refer to the Brazilian context and were collected in 2020 through an online survey, obtaining 353 responses from all regions of the country. The survey addressed impressions, attitudes and environmental conditions with regard to more open behaviors and dispositions about professional practice. This article focuses on a part of the issues (Q1-Q17) that contributed to compose a corporate perception of transparency, exploring opinions about peers and their own attitudes. Among other aspects, the results reveal contradictions between the representations that journalists make of themselves and their daily practices. They see themselves as more transparent than their actions show, which allows us to foresee some indisposition to open up the profession to the public. Among other factors, traits of a settled professional culture help to justify such behaviors. Keywords: Transparency. Professional perception. Brazilian journalists.

A Lei de Acesso à Informação (LAI) completa uma década em 2021. Sancionada em 18 de novembro de 2011, a Lei $n^{\circ} 12527$ foi resultado do trabalho coordenado por parcelas organizadas da sociedade, que convenceram os agentes políticos da necessidade de um novo regime de verdades, um modelo no qual, na República, a transparência deve ser a regra e o segredo, a exceção. À época, a Associação Brasileira de Jornalismo Investigativo (Abraji) teve papel de destaque, promovendo debates

Este artigo é resultado da pesquisa Transparência no jornalismo: valor ético, compromisso público e desafio prático para profissionais e a indústria, financiada pelo Conselho Nacional de Desenvolvimento Científico e Tecnológico (CNPq), e faz parte do projeto Communication and Democracy: Media Accountability, Public Service Media, Internet Access and the Right to Information in Germany and Brazil, financiado pela Coordenação de Aperfeiçoamento de Pessoal de Nivel Superior (Capes) e Deutscher Akademischer Austauschdienst (DAAD), da Alemanha. O autor agradece aos pesquisadores Dairan Mathias Paul, Denise Becker e Bianca Anacleto, que contribuiram para a coleta de dados desta etapa da investigação.

Universidade Federal de Santa Catarina, Florianópolis, SC, Brasil. 
sobre a necessidade de um instrumento social que permitisse maior accountability, envolvendo outros atores sociais na elaboração, discussão e aprovação da lei no Congresso Nacional. Essa participação sinaliza a preocupação de parte dos jornalistas com a visibilidade dos atos públicos na sociedade contemporânea, o que, não só facilita seu trabalho cotidiano, como também aponta para a informação como um bem público, um direito individual e coletivo.

Como as mudanças para o novo modelo transparência como regra e sigilo como exceção - incidiriam sobre todas as esferas de poder e a adoção de paradigmas nunca é imediata, os legisladores optaram por um vacatio legis de 180 dias, periodo necessário para ajustes, até que o novo marco pudesse entrar em vigor. O prazo foi importante para que o país se preparasse. No entanto, sabemos que transformações culturais levam bem mais tempo. Assim, embora dez anos tenham se passado, parte substancial da população ignora a LAI, outra porção minúscula a utiliza e, ainda, existem governantes que a consideram um entrave político e administrativo.

Nos últimos anos, não foi apenas o poder público que precisou se adaptar a novos regimes de visibilidade e publicidade. Setores influentes da iniciativa privada têm adotado práticas que reforcem os conceitos de responsabilidade social, boa governança e compliance (OLIVER, 2004). A transparência nos negócios é entendida como um fator para aumento da confiança nos sistemas e como resposta ou prestação de contas a acionistas, clientes e demais elementos da cadeia produtiva. Esse movimento é recente e tem se espalhado com mais vigor nos últimos 30 anos.

No mundo político, a transparência entrou para a agenda dos governantes no meio da década de 1980, motivada, basicamente, por duas razões: o senso comum de que a corrupção estava crescendo na sociedade e a sensação de distanciamento do Estado, em relação às demandas coletivas. Sendo necessário estancar a deterioração da confiança nas instituições, o sistema político aquiesceu que alguma concessão deveria ser feita. Aumentar a visibilidade de seus atos e decisões e vir a público periodicamente para dar satisfações pareceram gestos possíveis no estreito espaço de manobra da política (BOWLES, HAMILTON \& LEVY, 2014). Entidades, grupos e cidadãos deram passos na mesma direção, criando organizações e movimentos que exigiam mais transparência pública e mais participação nas tomadas de decisão, ao mesmo tempo em que tornavam mais sofisticados os mecanismos de controle e acompanhamento social. Vistos de longe, Estados e sociedades parecem realizar uma elegante e bem ensaiada contradança, mas os pontos de tensão e colisão de interesses são mais numerosos que os de convergência. Isto é, no tema da transparência, a realidade é mais conflitiva que serena.

De forma mais extensiva, o assunto tem se espalhado, também, para outros quadrantes da vida, como a sociotécnica. Na segunda década do século XXI, quando as mídias sociais ajudam a moldar a existência comum e gigantescos conglomerados tecnológicos monopolizam mercados rentáveis e influentes, algumas vozes cobram mais transparência algoritmica. Se Facebook, Google, Instagram e YouTube devoram camadas generosas de nossos tempos, se orientam comportamentos coletivos e se alimentam de montanhas de dados pessoais de seus usuários, por que não nos dizem como isso é feito e que impactos gera em nossas existências? Se as demais big techs incidem de forma tão determinante em nosso cotidiano, por que suas plataformas digitais negam informações sobre funcionamento de sistemas e tomadas de decisões que impactam bilhões de pessoas? (FILGUEIRAS \& ALMEIDA, 2021). Essa opacidade está por trás de estruturas de aumento e perpetuação de desigualdade social (O'NEIL, 2020) e da conjugação do acirramento do capitalismo, da concentração de riqueza e da exploração de dados pessoais? (ZUBOFF, 2020). A transparência dos algoritmos pode ser resposta factivel do sistema tecnológico aos clamores sociais?

\section{Transparência e jornalismo}

Desde meados da década de 1980, o jornalismo é um dos maiores amplificadores das vozes que 
defendem a transparência nas sociedades. 0 ascendente clamor pela transparência na política funcionou como um catalisador para reportagens e coberturas dedicadas ao tema. Para as redações, atos obscuros dos governantes dificultavam outra pauta importante para a sociedade: o combate à corrupção. Essa correlação insuflou jornalistas e meios a trazerem à luz decisões e atitudes que antes ficavam restritas aos círculos do poder. Paralelamente, foi despertado um interesse maior pelo acompanhamento de políticas públicas, o que só funcionaria bem com mais visibilidade.

Apesar de o jornalismo ser um aliado da transparência, essa condição não o impediu de se manter bastante opaco nesses anos todos.

No plano organizacional, o jornalismo é uma atividade desempenhada em empresas majoritariamente de controle privado, dissemina a mentalidade de que não precisa ser transparente, nem que tenha que prestar contas públicas de suas ações. Esse raciocínio ajuda a blindar a organização noticiosa do olhar coletivo, preservando os segredos dessa indústria e, consequentemente, ocultando da sociedade interesses, vieses e relacionamentos que possam ser questionados. Na prática, o veículo jornalístico é instado a fiscalizar os poderes e cobrar deles transparência, ao mesmo tempo em que habita um plano que não é alcançado pelas mesmas exigências.

No plano individual, jornalistas também estão imersos em uma cultura profissional que rechaça a transparência de seus procedimentos, porque isso pode levar a riscos para as fontes, para a informação, para si mesmos ou para as práticas decantadas historicamente nas redações. Não é à toa que, diante de qualquer interpelação, jornalistas sintam-se ameaçados pessoalmente ou vítimas de censura e perseguição por outros atores.

No mundo do jornalismo, a transparência assume a forma de uma faca de dois gumes: serve de instrumento para aumentar a força e a potência de sua realização e funciona como a arma que pode fragilizar sua mística e cânone. Em nome do direito público à informação, repórteres utilizam a LAl, acessam portais de transparência, pressionam governantes e servidores para que se expliquem. Em nome da autopreservação, jornalistas reivindicam seus sigilos profissionais, e empresas jornalisticas fecham-se ao escrutínio público, escondendo seus quadros societários, atrelamentos políticos e composições ideológicas.

No mundo do jornalismo, a transparência assume, também, uma corporeidade fantasmagórica. Em vários momentos, ela se materializa com peso, nitidez e importância, quando é invocada para que governos, sujeitos e organizações publicizem seus atos e resultados. Quando conveniente, a transparência se esfarela de tal forma, que some por completo, como se nunca tivesse existido.

É essa condição contraditória, complexa, dinâmica e relacional da transparência com o jornalismo que nos interessa neste artigo. Buscamos saber como os jornalistas brasileiros se relacionam com a transparência, como a percebem em seus pares e como eles próprios agem no seu cotidiano. A transparência não é uma completa estranha nos estudos de jornalismo, e alguns autores já a trataram, tanto numa perspectiva deontológica - e idealizada (BOWLES, HAMILTON \& LEVY, 2014; FRANZONI \& LISBOA, 2018) - quanto prática - principalmente ressaltando as dificuldades para implementá-la (HAN, 2017; EBERWEIN, FENGLER \& KARM, 2019; BERGER \& OWETSCHKIN, 2020).

Maia (2008), por exemplo, posiciona a transparência como uma regra ética, que pode atuar como facilitadora da democratização no processo de produção jornalistica. Van der Wurff e Schönbach (2011) recorrem a 60 experts da área para apontar valores importantes do jornalismo, destacando a transparência, dentro de práticas possiveis. Segundo esses autores, não há um padrão único, mas uma norma abrangente, que inclui relacionamento com fontes e públicos, e ações de justificação de decisões e posturas, de modo a galvanizar práticas e locais de emissão de informação. Fengler et al. (2013) reúnem estudos sobre transparência e media accountability do projeto MediaACT, que reuniu países europeus e árabes, mapeando esforços regionais, ações nas empresas e redações e sugestões de politicas públicas para educadores e policy makers. 
Apesar do apelo cada vez mais frequente por práticas sociais de transparência, a implantação de tais práticas reserva, em si, riscos e dificuldades, apontam Allen (2008) e Craft e Heim (2009), condição que ajuda a explicar uma certa indisposição para tal visibilidade.

Essas dificuldades podem dificultar a disseminação de uma cultura de mais abertura social do jornalismo, mas não invalida esforços já dispendidos. É útil e necessário compreender, também, internamente como o jornalismo considera tais práticas.

Para entrever esse cenário, recorremos à categoria profissional, composta, justamente, por quem fica exposto ao escrutínio público e, ao mesmo tempo, é cada vez mais instado a dialogar com as audiências.

Na Espanha, por exemplo, Chaparro-Domínguez, Suárez-Villegas e Rodríguez-Martínez (2019) vinculam a prestação de contas dos jornalistas ao sentimento de responsabilidade profissional, e Ramón, Mauri-Rios e Diaz-Campo (2020) recorrem às percepções de jornalistas e cidadãos para aferir os instrumentos de accountability dos meios espanhóis. Na Ucrânia, Grynko (2012) também se debruça sobre o entendimento dos jornalistas daquele pais, para entender a transparência na midia, descrevendo as dificuldades típicas de uma nação historicamente dependente, com democracia instável e jornalismo incipiente.

No Brasil, Paulino e Gomes (2019) aplicaram um instrumento adaptado do projeto MediaACT a 110 jornalistas. Entre as conclusões, observa-se o entendimento de que ainda há muito a ser feito pelas organizações jornalísticas, "para que se possa alcançar uma verdadeira e ampla transparência e prestação de contas pelo conteúdo produzido", e que accountability é percebida como elemento importante "para assegurar a liberdade de imprensa" (PAULINO \& GOMES, 2019, p. 15).

Seibt e Fonseca (2019), por sua vez, articulam a transparência como um princípio normativo, sobretudo em práticas como fact-checking, emergente na última década como antídoto potencial à desinformação. Gerhke (2020) aproxima a lupa sobre a categoria profissional, concentrando-se em um grupo de 36 jornalistas de dados, para ver como concebem e atuam no que se refere à transparência. Entre os resultados, a autora ressalta uma marcante disposição desse grupo para ser transparente todos os dias (diferentemente do que se observa nas organizações de mídia) e uma forte correspondência entre transparência, ética e credibilidade.

Nesta pesquisa, concebemos transparência no jornalismo como uma disposição voluntária ou estimulada à abertura dos profissionais sobre seus procedimentos técnicos, sobre suas preocupações éticas e com relação a detalhes de seu cotidiano produtivo, que não são apresentados compulsoriamente ao público. Transparência no jornalismo tem a ver, portanto, com uma postura, inclinação, gestos e/ou atitudes que aumentem a visibilidade das práticas desses profissionais e das organizações ou arranjos produtivos que os congregam. Tal fator pode levar à prestação de contas ou sistemas de accountability. Pode ser considerada uma virtude ética, um traço cultural, uma condição de trabalho, uma normativa interna ou uma predisposição para ação.

Objetivando contribuir para uma compreensão mais ampla, retornamos à categoria para colher outros elementos da percepção dos jornalistas brasileiros sobre a transparência em sua atividade. A pesquisa foi desenvolvida num contexto em que as sociedades global e brasileira demonstravam grande preocupação com a opacidade. Em 2020, uma das queixas mais frequentes durante a pandemia foi a falta de transparência pública sobre dados de infectados e mortos pela Covid-19 e sobre as formas desse combate pelos governos. Por decisão metodológica, não exploramos os impactos da epidemia sobre a disposição dos jornalistas em serem mais transparentes. As incertezas sobre a doença e a capacidade de respostas a ela eram muitas na segunda metade de 2020, quando aplicamos nosso instrumento de pesquisa. Mantivemos o foco no objetivo central do estudo que motivou este artigo. Por isso, nosso questionamento quis compreender se os jornalistas são mais sensiveis e abertos à transparência quando se trata de sua própria atividade. 


\section{Materiais e métodos}

Para aferir as percepções dos jornalistas brasileiros sobre transparência na sua prática cotidiana, recorremos a uma survey eletrônica com 27 questões abertas e de múltipla escolha (classificadas como Q1-Q27). Destinado apenas a profissionais que atuam em redações, o questionário foi hospedado em um endereço da internet, cujo link foi distribuido em listas de e-mails e encaminhado a sindicatos, empresas e entidades de classe. Para ampliar a capacidade de recebimento de respostas, convites de participação da pesquisa foram publicados em sites, blogs e redes sociais.

Os sujeitos que se dispunham a responder a pesquisa tinham acesso a informações detalhadas sobre os objetivos do estudo, suas técnicas, financiamento, pesquisador responsável e formas de contato. Também, poderiam baixar uma versão do Termo de Consentimento Livre e Esclarecido em formato $\mathrm{PDF}^{2}$, que especificava garantias de anonimato, sigilo e confidencialidade, além de ressarcimento e indenização em casos de danos decorrentes da pesquisa, bem como uso, armazenamento e guarda de dados pessoais.

Antes de responderem, os sujeitos deveriam marcar um campo no formulário confirmando ciência dos procedimentos e aceitação em participar da pesquisa. O questionário passou por pré-testes, que não identificaram danos psicológicos, fisicos, laborais ou emocionais nos participantes, o que permitiu calibrar o instrumento de investigação. Todos os aspectos metodológicos foram avaliados e aprovados pelo Comitê de Ética em Pesquisa com Seres Humanos da Universidade Federal de Santa Catarina ${ }^{3}$ (parecer n 4.079.125, de 9 de junho de 2020).

O questionário ficou ativo para recepção de respostas entre os dias 15 e 30 de setembro de 2020 e, ao longo do periodo, contamos com o auxilio de sindicatos, meios de comunicação, jornalistas, associações e pesquisadores na divulgação da pesquisa. Foram coletadas 358 respostas, das quais cinco foram descartadas, porque seus autores não haviam marcado o campo de anuência. Essa condição nos pareceu uma exigência inegociável, tendo em vista os cuidados de ética com seres humanos que adotamos nesta pesquisa.

Saneada, a base de dados totalizou 353 sujeitos, que compõem uma amostra equilibrada, geograficamente representativa, multigeracional e diversificada no exercício das funções jornalisticas, conforme se pode ver a seguir.

Quadro 1 - Síntese da população da pesquisa

\section{Faixas etárias (anos)}

\begin{tabular}{|c|c|c|c|c|c|}
\hline 18 a 29 & 30 a 39 & 40 a 49 & \multicolumn{3}{|l|}{ Mais de 49} \\
\hline $26 \%$ & $31,2 \%$ & $20,4 \%$ & \multicolumn{3}{|l|}{$22,4 \%$} \\
\hline \multicolumn{6}{|c|}{ Tempo de carreira no jornalismo (anos) } \\
\hline Menos de 5 & 6 a 10 & 11 a 20 & \multicolumn{3}{|l|}{ Mais de 20} \\
\hline $25,2 \%$ & $19 \%$ & $24.9 \%$ & \multicolumn{3}{|l|}{$30,9 \%$} \\
\hline \multicolumn{6}{|c|}{ Região de atuação profissional } \\
\hline Sul & Sudeste & Centro-Oeste & Nordeste & \multicolumn{2}{|l|}{ Norte } \\
\hline $27,3 \%$ & $36,1 \%$ & $13,6 \%$ & $18,5 \%$ & \multicolumn{2}{|l|}{$4.5 \%$} \\
\hline \multicolumn{6}{|c|}{ Funções jornalísticas que exercem } \\
\hline Repórter & Editor & Produtor & Repórter de imagem & Mais de uma & Outras \\
\hline $25,9 \%$ & $13,4 \%$ & $3,7 \%$ & $1,4 \%$ & $27.5 \%$ & $28,1 \%$ \\
\hline
\end{tabular}

Fonte: Próprio autor, com base nos dados oferecidos pelos participantes na survey. 
As questões de múltipla escolha permitiram a obtenção de resultados quantitativos, e as respostas às questões abertas foram interpretadas por meio de análise de conteúdo, gerando dados qualitativos. A próxima seção destrincha os resultados de 17 das 27 perguntas do questionário, centradas, principalmente, sobre impressões, atitudes pessoais e percepções dos jornalistas brasileiros sobre a transparência na sua profissão (Q1-Q17).

\section{Transparência como valor}

A percepção da categoria é que a transparência não é desprezada entre os jornalistas no Brasil. Em Q1, perguntamos "você acha que jornalistas valorizam a transparência?", e 66,2\% responderam "sim", enquanto que pouco mais de um quinto $(22,7 \%)$ negou. Outros $11,1 \%$ assinalaram não saber.

Em Q2, indagamos aos participantes o que lhes dava tal impressão. Uma parcela dos respondentes vinculou a transparência a aspectos da deontologia ou a valores que organizam e sustentam a atividade. Assim, a transparência é "princípio fundamental da profissão", "é um dos pilares do jornalismo", "faz parte do nosso trabalho", "é fundamental ao trabalho da reportagem", e tem a ver com "comprometimento profissional e ético" ou à "função social" do ofício. Alguns sujeitos apontaram que a valorização da transparência facilita o trabalho dos jornalistas, pois está interligada à credibilidade. Ao mesmo tempo, outros apontaram para dificuldades que parecem, também, compor certa essencialidade da profissão: "em geral, não gostamos de divulgar como trabalhamos"; "jornalistas tendem a ser mais reservados com as informações pela natureza profissional". Alguns respondentes reconheceram a dificuldade de lidar com o conceito, que tem muitas variantes na lida diária, funcionando, tanto como um exercício de "honestidade intelectual ou comportamental" quanto como fator que fragiliza o profissional, deixando-a vulnerável, em um ambiente bastante competitivo. Um sujeito da pesquisa respondeu: "acho também que pensar nisso nos faz pensar sobre o quão ética está sendo nossa atuação, o que, no mais das vezes, pode ter uma resposta em área cinzenta".
Como afirmou outro participante, "uma coisa é valorizar, outra é fazer transparecer".

Algumas respostas permitiram perceber que aspectos laborais ou estruturais das organizações jornalisticas podem se colocar como entraves adicionais à implementação de práticas mais transparentes. Foi o que se colheu nas respostas que apontam para rotinas aceleradas nas redações, pouca liberdade de ação dos profissionais e o contraste entre a disposição de repórteres e a resistência de editores e colunistas. Para um dos respondentes, parece haver "pouco esforço para apontar de forma objetiva como as informações foram apuradas. Off [-the-record] é generalizado e estimulado pelas chefias, até como forma de 'comprovar teses', apurar mais rápido, recuperar logo o que colegas já deram..."

Outras respostas à Q2 reforçaram o entendimento de que a transparência não é um objeto teórico, sendo impactado, constantemente, por fatores concretos. A sobrecarga de trabalho nas redações, por exemplo, também contribui para evitar a abertura:

A maioria faz o trabalho no automático e vai
embora, sem muito raciocinio sobre os me-
andros do jornalismo e as idiossincrasias da
profissão. Mesmo os mais experientes estão
se equilibrando para se manter no cargo e
agradar uma chefia, bater metas. (Resposta
de um dos participantes à Q2).

Outras respostas apontam para dificuldades dos jornalistas em compreender melhor o que significa ser transparente: "é um conceito ainda pouco entendido por alguns"; "como discurso fácil, é bastante atraente a todos. Quando entra no detalhe, é mais complicado. A ideia que muitos fazem do que é transparência não passa muito da superfície".

A afirmação de um sujeito da pesquisa chama a atenção para mais limitações: "valorizar a transparência é uma coisa. Poder exercê-la é diferente". Ecoa a percepção de que os jornalistas estão mais propensos à transparência do que às organizações que os empregam. Essa subordinação invalida certos esforços: "o jornalista, na maioria dos casos, tem que estar de acordo com as ideias do veículo de comunicação ao qual trabalha, e nem sempre a empresa vai aceitar determinadas coisas. Isso 
torna o trabalho do jornalista, às vezes, não tão transparente como deveria". Na mesma direção, outro participante atesta que a transparência é valorizada "quando convém à empresa ou à pauta" e explica: "é comum o discurso 'conseguido com exclusividade' para informações que foram vazadas de órgãos públicos, documentos de 'fontes anônimas', ao invés de creditar como 'fontes que preferem não se identificar' ou, ainda, dados escavados de portais públicos, apenas tratados e interpretados pela equipe do jornal".

Ainda entre as respostas, emergem elementos que apontam para algum cinismo entre os jornalistas, que cobram transparência de órgãos públicos e governos, mas são refratários quando se trata de sua profissão: "transparência dos outros, mas não sobre a sua própria atividade"; "jornalistas valorizam a transparência nos outros [...] Da porta da redação para dentro, a transparência, sobretudo, de processos internos, é pouco valorizada"; "em geral, jornalistas não costumam ser críticos em relação a si próprios e a sua função". Um dos respondentes explica que a transparência é "encarada muito mais como dever das fontes e instituições do que do próprio jornalismo e de seus profissionais, seus processos e interesses". Outro considera que os jornalistas não refletem tanto ainda:

Pouco se mostra ao público geral do processo de produção jornalistica; até mesmo o contato com uma redação ou repórter é difícil. O panorama tem se transformado timidamente nos últimos dois ou três anos, diante da necessidade de reconquistar a credibilidade e a confiança da audiência. (Favor incluir a referência).

Um terceiro respondente foi categórico: "querem transparência para os objetos das pautas, mas as empresas jornalísticas não resistiriam ao seu próprio escrutínio jornalístico". A razão para este comportamento talvez esteja, justamente, nos "métodos questionáveis para conseguir a informação (mentir, manipular, etc.)", arrisca outro respondente.

\section{Transparência na prática dos colegas}

Em Q3, perguntamos aos 353 participantes se jornalistas agem com transparência ou se esforçam para parecer transparentes. A maior parte estabeleceu uma ligação positiva entre jornalistas e transparência: 61,6\% consideram que seus pares atuam de forma transparente ou, pelo menos, buscam fazê-lo. Outros 23,8\% não veem dessa forma, e 14,6\% foram inconclusivos, afirmando não saber.

Em Q4, questionamos os motivos de tais crenças. As respostas reverberaram algumas apresentadas à Q2. No geral, os sujeitos consideram que jornalistas se esforçam para ser transparentes, porque essa postura traz vantagens, como reconhecimento profissional por parte do público, acréscimo de credibilidade e maior aceitação social. Algumas respostas exemplificam tais posições: "não agir com transparência, em tempos de internet, faz com que o jornalista entre em descrédito facilmente"; "é questão de imagem. Uma imagem de transparência reverbera maior credibilidade e autoridade sobre o assunto ou cobertura, ou até do veículo como um todo"; "com as pessoas tendo acesso a tantas informações, é preciso que o profissional seja transparente!"; "ser transparente gera uma integridade profissional".

Um participante da pesquisa aponta que:

\begin{abstract}
Em tempos de fake news e de questionamento da imprensa tradicional, é cada vez mais fundamental ser transparente em relação a como se obteve a informação e detalhar o máximo possivel quem são as fontes e o contexto da situação. Não se trata de revelar suas fontes, caso elas sejam sigilosas, mas deixar claro para o leitor todos os aspectos que envolvem aquele caso. (Favor incluir a referência).
\end{abstract}

Percebe-se que a transparência se coloca, para alguns, como catalisadora de uma condição mais positiva, como a aceitação pública, o reforço da autoridade jornalística ou incrementos no capital social.

Os participantes da pesquisa que não enxergam esforços por mais transparência atribuem isso à falta de estímulo das empresas, receio de julgamentos do público e enfraquecimento de suas práticas profissionais. De acordo com um participante, existe um:

Receio de perderem poder diante da exposição do modus operandi da profissão e, principalmente, pela falta de cultura politica de accontability nas redações jornalisticas, o que 
leva os jornalistas a temerem represálias e demissões com a busca pela transparência em sua rotina operacional.

Outro afirmou que "há casos também em que, simplesmente, o jornalista não deseja ser transparente", outro, ainda, reputou que a maior parte dos esforços nesse sentido são "marketing: se houvesse transparência real de como as decisões são tomadas em uma redação, muitos não leriam mais".

Tais justificativas puderam ser ratificadas nas respostas à Q5, que perguntava as razões de tais comportamentos. Novamente multivariadas, as rinformações permitem entrever que, além da falta de estímulo, precarização profissional e pressões internas, outros fatores também explicam por que o jornalismo nacional não é mais transparente: arrogância, autoproteção, medos variados e a insistência de uma imagem herdada. As afirmações a seguir ilustram esses fatores: "eles acham que já sabem tudo"; "arrogância é o grande pilar do jornalismo. Sem minha arrogância, eu jamais teria progredido na carreira"; "é a arrogância de quem se julga numa posição superior"; "é pelo desejo de serem os detentores da sabedoria, da informação. Afinal, informação é importante, é poder. Acredito que jornalistas têm também dificuldade em serem questionados"; "é corporativismo, sindrome de pequeno poder"; jornalistas têm "receio de ser diferentes do grupo"; "por medo de retaliações e/ou demissões"; "para evitar ensinar à concorrência os canais de informação". Para um dos respondentes, acontece uma "reprodução automática de um modelo de jornalismo, no qual a imprensa tinha crédito por estar falando 'sempre' a verdade. Isso se perdeu. Há outro problema: o sucateamento do trabalho jornalístico. Falta tempo de explicar a reportagem". Para outro participante da pesquisa, a pouca transparência nas redações "é uma questão cultural, calcada no esforço para que o jornal baste como fonte de informação, para que o leitor não se informe pelas fontes primárias e, também, para que a informação pareça exclusiva e outros repórteres tenham dificuldade em replicar".

Até então, nossas perguntas tentavam capturar a percepção dos sujeitos sobre as práticas de jornalistas de uma forma geral. Isto é, objetivávamos recolher as percepções dos participantes sobre as posturas e atos dos seus pares. A partir da sexta pergunta, alteramos o foco, levando os sujeitos a pensarem sobre suas próprias atitudes.

\section{Recursos de transparência utilizados}

Em Q6, indagamos: "como jornalista, você já usou informações de bases de dados públicas em suas matérias?". A grande maioria - 87,2\% respondeu afirmativamente. Perguntamos em que situações (Q7). As respostas compuseram um cenário bastante amplo, que engloba a busca de dados nos três poderes, nas esferas administrativas federal, estaduais e municipais, em autarquias, estatais e órgãos, inclusive para a obtenção de informações pessoais de servidores e detentores de cargos públicos. Os sujeitos da pesquisa afirmaram, também, que buscam dados de empresas privadas que mantêm relações com governos, mas percebe-se com muito menos frequência e com um olhar mais detido sobre eventuais desvios de comportamento dos governos.

As respostas à Q7 mostraram que a apuração em bancos de informação atende a reportagens em diversas editorias, com destaque para política, economia, saúde, segurança pública, obras e educação, seja para acompanhar gastos públicos, contratos e pagamentos, seja para comprovar denúncias ou complementar dados imprecisos ou não fornecidos em portais de transparência.

Ainda explorando os recursos e dispositivos de transparência pública que os jornalistas têm no Brasil, em Q8, questionamos se os participantes já tinham feito pedidos pela LAI. As respostas foram bem distintas das colhidas em Q6, mostrando desinteresse, indisposição, despreparado técnico ou simples desconhecimento sobre o uso profissional da legislação: 58,8\% disseram que nunca fizeram pedidos pela LAI (Qg). Aos que lançaram mão desse recurso, perguntamos em que situação isso se deu (Qg), e a maior parte dos pedidos solicitou: remuneração de servidores e documentos não disponibilizados em portais de transparência; listagens de fornecedores, funcionários comissionados ou terceirizados; integra de 
processos judiciais ou administrativos; relatórios internos de ministérios, secretarias e departamentos; processos em tribunais de contas; descritivos de despesas com verbas públicas; detalhamento de programas, projetos e políticas públicas. As respostas permitem aferir que os pedidos mais frequentes são dirigidos ao Poder Executivo, seguido dos parlamentos, sobretudo nas escalas federal e estadual. Percebe-se, pelas respostas espontâneas à Q9, que há menos petições pela LAl ao Poder Judiciário.

\section{Transparência em relação às fontes}

Na décima questão do formulário (Q10), exploramos um tema delicado da prática jornalística: "com que frequência você revela suas fontes nas matérias?" O assunto é cercado de suscetibilidades, porque tem nuances que vão do direito constitucional de sigilo profissional ao dever deontológico da proteção das fontes, passando pelo cultivo e preservação de acessos, que se traduzem em informações exclusivas, por exemplo. Uma parcela de 12,3\% disse "sempre" e outra de 9,4\%, "nunca". Um pouco mais que o quinto $(20,8 \%)$ respondeu "quase sempre", mas a maior parte dos sujeitos da pesquisa - 57.5\% - assinalou a alternativa "só não revelo quando me pedem sigilo", facultando às fontes a decisão sobre como agir.

Ainda no terreno do relacionamento com as fontes, perguntamos se os participantes aceitavam declarações em off-the-record. As respostas à Q11 sinalizaram uma clara disposição em estabelecer tais pactos: as respostas "sim, sempre" $(24,4 \%)$ somadas às de "às vezes" (63,2\%) alcançaram uma fatia de pouco mais de sete oitavos da população ouvida (87,6\%). Apenas $12,4 \%$ rechaça o expediente: "nunca aceito".

Em Q12, perguntamos se os participantes compartilham contatos e fontes com seus colegas de trabalho. As respostas dividem as redações brasileiras: 50,9\% reconhecem a prática com naturalidade, enquanto que 45,2\% condicionam o compartilhamento ("depende"). Apenas 4\% afirmaram não trocar informações sobre fontes e contatos com seus pares.
Questionamos, ainda aos sujeitos, se eles dão detalhes de como conseguiram informações em suas reportagens. Menos de um terço marcou a alternativa "sim, sempre" (28\%), ao passo que 57,1\% assinalaram "às vezes", e 14,9\% responderam "não".

A pouca disposição de transparência sobre os métodos de obtenção de informação pode estar relacionada a uma percepção de irrelevância, ou mesmo de incerteza, difundida entre os jornalistas. Indagamos se os sujeitos consideravam importante contar esses detalhes ao público, e metade dos respondentes disse "às vezes", 5,1\% negaram. Uma parcela expressiva de 44,3\% destacou tal importância.

\section{A transparência impossível}

Em Q15, perguntamos aos participantes se acreditavam existir "rotinas ou práticas jornalisticas que não podem ser transparentes" e quais seriam elas. Para os ouvidos na pesquisa, a principal situação justificada de ocultamento no jornalismo foi a proteção da fonte de informação. Dezenas de respostas afirmaram, espontaneamente, que a transparência não deve ser esperada ou exigida quando se atende a um pedido de anonimato ou quando se decide não publicar a identificação da fonte ou detalhes que levem a isso. Nessas situações, a ausência da transparência ajuda a preservar vida, saúde ou integridade, e alguns participantes lembraram que a atitude é prevista na lei e nos códigos deontológicos. É justificável não publicar "quando a fonte pede para não ser identificada por razões de segurança física ou porque sua função não the permite revelar a informação dada".

Análogas foram as respostas que defenderam a opacidade para proteger terceiros - geralmente, pessoas mencionadas por fontes - e os próprios jornalistas. Mas houve quem frisasse que, não só informações e identidades deveriam ser mantidas em segredo, mas também o relacionamento de jornalistas e fontes, "particularmente em off-the-record ou quando extrapolam a relação profissional".

O jornalismo investigativo também é tratado como uma excepcionalidade de transparência aceita pelos sujeitos da pesquisa. Nesses casos, 
"as rotinas de apuração não podem ser transparentes enquanto a apuração está sendo feita, pois pode prejudicar a qualidade e o andamento da investigação"; em reportagens do tipo, "nem sempre se revela como se obteve informações" e, em algumas vezes, "práticas investigativas exigem que o jornalista não aja com transparência". Um respondente ponderou que "no processo investigativo é necessário o sigilo, mas, depois de ter as informações oficiais, é importante destacar como se obteve o acesso".

A suspensão da transparência parece ser uma demanda passageira nessas situações, diferente de outro temor: o de que a publicação ilimitada de informações desperte a atenção dos concorrentes e comprometa a exclusividade ou protagonismo na cobertura. Assim, é importante evitar "qualquer rotina ou prática que possa expor uma fonte ou que dê munição para a concorrência seguir o mesmo caminho". "Quando a gente cita uma fonte, também abrimos aos concorrentes a nossa estratégia de ação. Se a omissão da fonte não compromete a credibilidade da informação e a fonte pode render informações futuras, ela pode ser preservada", defendeu um respondente.

\section{A opacidade esperada}

Posicionamentos variados foram registrados quando se indagou sobre práticas aceitáveis de opacidade no jornalismo. Num extremo, houve quem dissesse que tudo poderia ser mostrado e publicizado - "desde os salários, passando pelo financiamento do veículo, e principalmente os métodos" - e houve quem demonstrasse desprezo por essa abertura - "transparência demais tira o charme da coisa, é como sexo sem preliminares".

Entre os extremos, observamos reflexões bastante matizadas sobre o que é ser transparente no jornalismo e sua complexidade efetiva. Um respondente afirmou: "não acredito que existam práticas que não possam ser transparentes, mas também acredito que jornalismo não é reality show. O protagonismo tem que ser do assunto, não do profissional. Existe uma linha tênue entre o 'isto aqui foi feito assim' e o 'veja como eu sou foda'". Outro sujeito afirmou: "na grande maioria das vezes, contar a 'odisseia' na notícia é apenas uma forma de supervalorizar uma matéria que passaria despercebida". Um terceiro considerou: "acho que existe uma diferença entre coisas que não são necessárias de se dizer e aquelas que não são ditas para evitar questionamentos". A resposta ajuda a alargar uma zona cinzenta das práticas, terreno em que apostam outros dois sujeitos da pesquisa: "transparência é diferente de publicidade. Alguns temas precisam ser mantidos em sigilo em casos especíicos, como segredos de justiça. Mas ser transparente é atuar com honestidade, informando o porquê de não divulgar certo tema, por exemplo"; "sigilo não é antônimo de transparência. Não identificar uma fonte, preservando-a de represálias, não é falta de transparência. Assim como não é obrigatório informar como se obteve um documento de interesse público, que pessoas ou instituições gostariam de manter em segredo".

Muitas respostas à Q16 - sobre por que tais práticas não deveriam ser transparentes - repetiram as razões para aceitá-las. A mais lembrada foi a preservação da fonte, que deve ter sua vida e segurança (inclusive juridica e de trabalho) protegidas pelo desconhecimento dos demais. Algumas informações, se reveladas, podem trazer riscos imediatos e adicionais, apontam os respondentes, que se preocupam, também, com a própria segurança, "pelo fato do Brasil ser um dos paises mais desiguais e perigosos para jornalistas trabalharem". Quebrar a promessa de um off-the-record para ser mais transparente, é tido como violação ética, desrespeito com a fonte, exposição desnecessária de pessoas vulneráveis e, até mesmo, não atendimento de um direito consagrado do jornalista, o sigilo profissional.

Um segundo tipo de resposta à $\mathrm{Q} 16$ diz respeito aos receios de que a transparência possa afetar os rumos da apuração e prejudicar o trabalho dos jornalistas. Desta forma, nem tudo pode ser dito para "não atrapalhar uma investigação", inviabilizá-la ou permitir ameaças ou obstruções, já que há "risco de perder a informação". Em certas ocasiões, ser muito transparente "pode extrapolar os limites da legalidade, como uma gravação escondida de 
uma reunião fechada", citou um respondente, ou, ainda, revelar os "modus operandi dos repórteres, detectando-se possiveis fontes, metodologias de arquivamento e de análise de dados, estratégias de checagem e divulgação". Da mesma forma, um participante foi categórico: "se você se identifica como jornalista, as portas fecham".

Em contraste com as respostas colhidas por Q15, em Q16, não vieram à tona as precauções relacionadas à concorrência, o que pode nos levar a inferir que a justificativa por mais ou menos transparência fique concentrada no círculo íntimo dos jornalistas, no qual convivem suas fontes, valores e esforços para garantir a informação. Onde são refletidas as situações práticas, sopesadas as consequências e tomadas as decisões.

Em Q17, perguntamos: "você acha que é suficientemente transparente com seu público?" A maior parte se vê como jornalistas muito transparentes $(68,2 \%)$, enquanto que $14,9 \%$ responderam "nem tanto" e apenas 5,2\% consideram não serem. Uma parcela de $11,7 \%$ respondeu não saber.

\section{Considerações finais}

Os resultados apresentados neste artigo se referem a uma fração das respostas colhidas na survey de setembro de 2020, concentradas nas impressões pessoais dos jornalistas sobre seus pares e na forma como avaliam as próprias atitudes cotidianas.

É nítido observar que a transparência é um valor que habita o horizonte da categoria, de forma espontânea e que, às vezes, até se choca com uma indisposição maior das organizações jornalísticas, da falta de estrutura local ou, mesmo, de um certo desprezo por parte dos gestores em comando.

É perceptivel, também, a convivência nas redações de dois grupos mais ou menos homogêneos: um, mais idealista e que se apega à transparência como conduta comum e desejável, e outro, mais cético, que problematiza sua implementação no cotidiano, pouco insistindo na sua operacionalidade. O primeiro grupo mostra-se mais disposto a assumir a transparência, porque enxerga, nela, vantagens concretas: aproxima os jornalistas dos públicos, presta contas do trabalho, fortalece sua credibilidade, divide o peso de algumas decisões. O segundo grupo é o que mais problematiza a implementação de práticas de transparência, reconhecendo a complexidade do conceito. Afinal, a transparência é uma categoria relacional, condicionada aos planos nos quais opera. Uma mesma empresa jornalistica pode estimular seus repórteres a serem transparentes quanto aos procedimentos de obtenção de informação, mas agir de forma opaca sobre as relações que mantém com grupos financeiros ou políticos, que interferem editorialmente no noticiário.

Nossa pesquisa não permite aferir como se dá a convivência desses dois grupos nas redações, nem se a coabitação pode levar a veículos mais ou menos transparentes. O que os resultados nos permitem dizer é que esse tensionamento se dissipa diante da necessidade de proteger fontes de informação. Quando se trata de atender a pedidos de sigilo ou quando se percebe que há riscos envolvidos, jornalistas reduzem a importância ou necessidade da transparência, aceitando sua suspensão ou, mesmo, o descarte. É importante frisar que os jornalistas ouvidos nesta pesquisa manifestaram maior zelo com a segurança das fontes do que com suas próprias. Os respondentes demonstram, também, menos preocupação com a concorrência. Ter a pauta roubada ou imitada não chega a ser um impedimento total da transparência por parte de alguns sujeitos da pesquisa.

As respostas revelaram, também, ligeiras contradições entre as representações que os jornalistas fazem de si mesmos e suas práticas cotidianas. Eles se veem mais transparentes do que apontam suas ações, o que permite perceber que a transparência e a abertura ao público não são prioridades para a categoria. Elementos da cultura profissional - decantados historicamente - , estruturas organizacionais e constrangimentos nos ambientes de trabalho são apontados como justificantes desses comportamentos.

Os participantes da pesquisa, também, aproximam rituais de transparência ao terreno da ética profissional. Essa particularidade garante à transparência maior permanência no imaginário 
coletivo e, quem sabe, mais condições para sua futura conversão em prática efetiva nas redações.

\section{Referências}

ALLEN, David S. The trouble with transparency: The challenge of doing journalism ethics in a surveillance society. Journalism Studies, v. 9, n. 3, p. 323-340, 2008. https://doi.org/10.1080/14616700801997224

BERGER, Stefan; OWETSCHKIN, Dimitrij. (Eds.). Contested transparencies, social movements and the public sphere. Cham: Palgrave Macmillan, 2020.

BOWLES, Nigel; HAMILTON, James T.; LEVY, David A. L. Transparency in politics and the media: Accountability and open government. Londres: I.B. Tauris, 2014

CHAPARRO-DOMINGUEZ, María A.; SUÁREZ-VILLEGAS, Juan C.; RODRIGUEZ-MARTíNEZ, Ruth. Media Accountability and Journalists: To Whom Do Spanish Professionals Feel Responsible? Journalism Practice, 2019. https://doi.org/10.1080/17512786.2019.1655470

CRAFT, Stephanie; HEIM, Kyle. Transparency in journalism: Meanings, Merits, and Risks. In: Wilkins, Lee; Christians, Clifford G. (Eds.). The handbook of mass media ethics. Nova York/Londres: Routledge, 2009.

EBERWEIN, Tobias; FENGLER, Susanne; KARMASIN, Matthias. (Eds.). Media accountability in the era of post-truth politics. Londres/Nova York: Routledge, 2019

FENGLER, Susanne; EBERWEIN, Tobias; MAZZOLENI, Gianpietro; PORLEZZA, Colin; RUSS-MOHL, Stephan. (Eds.). Journalists and Media Accountability: an international study of news people in the digital age. Nova York: Peter Lang, 2013

FILGUEIRAS, Fernando; ALMEIDA, Virgílio. Governance for the digital world: neither more State nor More Market. Cham: Palgrave MacMilian, 2021.

FRANZONI, Sabrina; LISBOA, Silvia. Jornalismo e efeito de transparência: definições na teoria e na práxis. Anais do $16^{\circ}$ Encontro Nacional de Pesquisadores em Jornalismo, São Paulo, 7 a 9 de novembro de 2018. Disponivel em: http://sbpjor.org.br/congresso/index. php/sbpjor/sbpjor2018/paper/viewFile/1507/908

GERHKE, Marilia. Transparency as a key element of data journalism: perceptions of Brazilian professionals. Computation + Journalism Symposium 2020, Boston, MA, USA, 2020.

GRYNKO, Anastasiia. Media transparency through journalist's interpretation: research in Ukraine. 174 f. Tese (Doutorado em Jornalismo) - Departament de Comunicació Audiovisual i Publicitat, Universitat Autònoma de Barcelona. Barcelona, 2012.

HAN, Byung C. Sociedade da transparência. Petrópolis: Vozes, 2017

MAIA, Maia R. A regra da transparência como elemento democratizador no processo da produção jornalística. Brazilian Journalism Research, v. 1 n. 1, 2008. https:// doi.org/10.25200/BJR.v4n2.2008.168
O'NEIL, Cathy. Algoritmos de destruição de massa. Santo André: Ed. Rua do Sabão, 2020.

OLIVER, Richard W. What is transparency? Nova York: McGraw-Hill, 2004.

RAMÓN, Xavier; MAURI-RIOS, Marcel; DIAZ-CAMPO, Jesús. Instrumentos de rendición de cuentas impulsados por los medios de comunicación: percepción de los periodistas y ciudadanos españoles. Revista de Comunicación, v. 19, n. 1, p. 221-241, 2020. https:// doi.org/10.26441/RC19.1-2020-A13

VAN DER WURFF, Richard: SCHÖNBACH, Klaus. Between Profesion and Audience: Codes of conduct and transparency as quality instruments for off- and online journalism. Journalism Studies, v. 12, n. 4. p. 407-422, 2011. https://doi.org/10.1080/1461670X.2010.506055

ZUBOFF, Shoshana. A era do capitalismo de vigilância. Rio de Janeiro: Intrínseca, 2020.

\section{Rogério Christofoletti}

Professor da Universidade Federal de Santa Catarina (UFSC), em Florianópolis, SC, Brasil, onde também atua como coordenador do Programa de Pós-Graduação em Jornalismo (2020-2022), e pesquisador do Conselho Nacional de Desenvolvimento Científico e Tecnológico (CNPq). Jornalista, mestre em Linguística e doutor em Ciências da Comunicação pela Universidade Federal de Santa Catarina (UFSC), em Florianópolis, SC, Brasil.

\section{Endereço para correspondência}

Rogério Christofoletti

Universidade Federal de Santa Catarina, Departamento de Jornalismo

Campus Universitário, Sala 147-E - Bloco A - CCE

Trindade - 88040-970

Florianópolis, SC, Brasil 